\title{
TARGETED PHOTOSENSITIZERS \\ WITH PHOTOINDUCED ANTITUMOR ACTIVITY \\ BASED ON NATURAL CHLORINS
}

\section{M.A. Grin, N.V. Suvorov, V.A. Pogorilyy, S.I. Tikhonov and A.F. Mironov}

Department of chemistry and technology of biologically active compounds, medicinal and organic chemistry, Institute of Fine Chemical Technologies, MIREA-Russian Technological University, 119571, Russia, Moscow, Prospect Vernadskogo, 86.

DOI: 10.19163/MedChemRussia2021-2021-145

E-mail: michael_grin@mail.ru

Recently to improve the effectiveness of anticancer therapy, polyfunctional drugs have been developed that provide targeted delivery of active pharmaceutical ingredients (API) to a tumor, reliable visualization of a tumor site, and an effective therapeutic effect leading to regression and tumor necrosis.

Due to their unique natural structure, chlorins and bacteriochlorins are theranostics, providing fluorescent tumor navigation and photodynamic therapy under light irradiation owing to the ability to generate reactive oxygen species. Focused light irradiation of the area of interest minimizes the side effects of pigments, including cutaneous phototoxicity and the need for patients to comply with the light regime. Nevertheless, targeted delivery of a photosensitizer to a tumor requires the introduction of additional vector molecules that provide receptor-mediated PS endocytosis into tumor cells.

In this work, chlorophyll a and bacteriochlorophyll a derivatives were used as a platform for the creation of the abovementioned PSs, to which a PSMA ligand was attached for targeted delivery to prostate cancer cells [1]; 3rd domain of alpha-fetoprotein for delivery to cells of various tumor lines and complexes of gold (I) and tin (IV) for target-oriented intracellular delivery of pigments [2]. All the proposed targeted drugs of the chlorin series exhibited photoinduced antitumor activity, which exceeded the cytotoxicity of chlorins without the introduced vector molecules. Thus, the combination of suitable drugs with different targets will allow for a personalized approach to treatment in oncology.

This work was carried out with the financial support of the Russian Foundation for Basic Research (№ 19-03-00302).

\section{References}

[1] N.V. Suvorov, A.E. Machulkin, A.V. Ivanova, A.M. Popkov, E.A. Bondareva, E.A. Plotnikova, R.I. Yakubovskaya, A.G. Majouga, A.F. Mironov, and M.A. Grin, Journal of Porphyrins and Phtalocyanins. 2018, 22, 1030-1038

[2] M.A. Grin, S.I. Tikhonov, A.S. Petrova, V.A. Pogorilyy, A.N. Noev, V.V. Tatarskiy, D.B. Shpakovsky, E.R.Milaeva, E.V. Kalinina, N.N. Chernov, A.A. Shtil, A.F. Mironov, A.D. Kaprin, and E.V. Filonenko, Anticancer Drug Research. 2020, 20, 49-58 